\title{
Dosimetric analysis of local failures in skull-base chordoma and chondrosarcoma following pencil beam scanning proton therapy
}

\author{
Lucas Basler ${ }^{1 *} \mathbb{D}$, Robert Poel ${ }^{1}$, Christina Schröder ${ }^{1}$, Alessandra Bolsi $^{1}$, Antony Lomax ${ }^{1}$, \\ Stephanie Tanadini-Lang ${ }^{2}$, Matthias Guckenberger ${ }^{2}$ and Damien C. Weber ${ }^{1,2,3}$
}

\begin{abstract}
Background: Despite combined modality treatment involving surgery and radiotherapy, a relevant proportion of skull-base chordoma and chondrosarcoma patients develop a local recurrence (LR). This study aims to analyze patterns of recurrence and correlate LR with a detailed dosimetric analysis.
\end{abstract}

Methods: 222 patients were treated with proton radiotherapy for chordoma $(n=151)$ and chondrosarcoma $(n=71)$ at the PSI between 1998 and 2012. All patients underwent surgery, followed by pencil-beam scanning proton therapy to a mean dose of $72.5 \pm 2.2 \mathrm{~Gy} \mathrm{VBE}_{\text {BE. }}$. A retrospective patterns of recurrence analysis was performed: LR were contoured on follow-up MRI, registered with planning-imaging and the overlap with initial target structures (GTV, PTV high-dose' $^{\prime}$ PTV $\left.V_{\text {low-dose }}\right)$ was calculated. DVH parameters of planning structures and recurrences were calculated and correlated with LR using univariate and multivariate cox regression.

Results: After a median follow-up of 50 months, 35 (16\%) LR were observed. Follow-up MRI imaging was available for 27 (77\%) of these recurring patients. Only one (3.7\%) recurrence was located completely outside the initial PTV (surgical pathway recurrence). The mean proportions of LR covered by the initial target structures were $48 \%$ (range 0-86\%) for the GTV, 70\% (range 0-100\%) for PTV high and 83\% (range 0-100\%) for PTV low. In the univariate analysis, the following DVH parameters were significantly associated with LR: GTV(V $\left.<66 G y_{\text {RBE }} p=0.01\right)$, GTV(volume, $p=0.02), \operatorname{PTV}_{\text {high }}(\max , p=0.02), \mathrm{PTV}_{\text {high }}\left(\mathrm{V}<66 \mathrm{GV}_{\mathrm{RBE}}, p=0.03\right), \mathrm{PTV}_{\text {high }}\left(\mathrm{V}<59 \mathrm{GV}_{\mathrm{RBE}}, p=0.02\right), \mathrm{PTV}_{\text {high }}($ volume, $p=0.01)$ and $\operatorname{GTV}(\mathrm{D} 95, p=0.05)$. In the multivariate analysis, only histology (chordoma vs. chondrosarcoma, $p=0.01$ ), PTV high $\left._{\text {(volume, }} p=0.05\right)$ and $\mathrm{GTV}\left(\mathrm{V}<66 \mathrm{~Gy}_{\mathrm{RBE}}, p=0.02\right)$ were independent prognostic factors for $\mathrm{LR}$.

Conclusion: This study identified DVH parameters, which are associated with the risk of local recurrence after proton therapy using pencil-beam scanning for patients with skull-base chordoma and chondrosarcoma.

Keywords: Chordoma, Chondrosarcoma, Skull-base, Pencil beam scanning proton therapy, Proton therapy, Patterns of recurrence, Dosimetric analysis

*Correspondence: Lucas.Basler@psi.ch

${ }^{1}$ Center for Proton Therapy, Paul Scherrer Institute, ETH Domain, Forschungsstrasse 111, 5232 Villigen, Switzerland

Full list of author information is available at the end of the article

\section{Background}

Chordoma and chondrosarcoma of the skull base are rare bone tumors [1-4] which are often located in close proximity to critical organs of risk (OAR), including but not limited to the brainstem, optic chiasm and optic nerves, making complete surgical resection of these tumors challenging and postoperative high-dose radiotherapy necessary in most cases [5]. original author(s) and the source, provide a link to the Creative Commons licence, and indicate if changes were made. The images or other third party material in this article are included in the article's Creative Commons licence, unless indicated otherwise in a credit line to the material. If material is not included in the article's Creative Commons licence and your intended use is not permitted by statutory regulation or exceeds the permitted use, you will need to obtain permission directly from the copyright holder. To view a copy of this licence, visit http://creativecommons.org/licenses/by/4.0/. The Creative Commons Public Domain Dedication waiver (http://creativeco mmons.org/publicdomain/zero/1.0/) applies to the data made available in this article, unless otherwise stated in a credit line to the data. 
Particle beam radiotherapy offers critical advantages compared to photon irradiation in these patients $[6,7]$, not only limited to protons but also carbon ions, as both are able to deliver high curative doses even to target volumes in close proximity to OARs, based on their finite range in tissue (Bragg-Peak), as well as an overall lower integral radiation dose delivered to the patient.

However, despite combined modality treatment involving surgery and adjuvant radiotherapy, a relevant percentage of chordoma and chondrosarcoma patients develop a local recurrence [8-10], which is most likely explained by the locally aggressive growth pattern. Unfortunately, in most cases, we currently lack prognostic parameters to assess the risk of local failure of an individual patient. Identifying patient, tumor or treatment characteristics, associated with an increased risk of local failure, could help in the clinical decision-making process.

In a previous study, we identified optic apparatus and/ or brainstem compression, histology and GTV volume as prognostic factors for the risk of local failure [11]. The present study aims to analyze patterns of recurrence and correlate local control with a detailed dosimetric analysis.

\section{Methods}

\section{Patient characteristics}

This study is based on overall 222 patients, which were treated with proton radiotherapy for chordoma $(\mathrm{n}=151$, $68 \%)$ or low-grade chondrosarcoma $(71,32 \%)$ at the Paul Scherrer Institute (PSI) between 1998 and 2012. Written informed consent was obtained from all patients and the study was approved by the local ethics committee (Kantonale Ethikkommission Nordwest- und Zentralschweiz (EKNZ, approval number 2020-01071) in accordance with 'good clinical practice' (GCP) guidelines and the Declaration of Helsinki. The patient's characteristics are detailed in Table 1 and have also been described in our previous analysis [11].

\section{Patient treatments}

All patients underwent surgery with 215 subtotal/near complete resections (96.8\%) and 7 complete resections (3.2\%). The gross tumor volume (GTV) was based on postoperative planning CT and MRI imaging and had a mean volume of $35.7 \pm 29.1 \mathrm{~cm}^{3}$. The clinical target volume (CTV) was based on the preoperative tumor extension including regions of suspected microscopic spread, including the surgical pathway based on institutional guidelines. The patients were treated with a larger (GTV or CTV expansion of $10 \mathrm{~mm}$ in most cases) low-dose $\mathrm{PTV}_{\text {low }}$ to a dose of $54 \mathrm{~Gy}_{\mathrm{RBE}}$ and received a sequential boost to a smaller (GTV or CTV expansion of $5 \mathrm{~mm}$ in most cases) high-dose PTV $\mathrm{Pigh}_{\text {hi }}$ to a dose of $74 \mathrm{~Gy}_{\mathrm{RBE}}$ or 70 $\mathrm{Gy}_{\mathrm{RBE}}$ for chordoma and chondrosarcoma respectively.
Proton therapy was administered using pencil-beam scanning (PBS) technique to a mean dose of $72.5 \pm 2.2$ with a prescribed dose of $74 \mathrm{~Gy}_{\mathrm{RBE}}$ for chordoma and 70 $\mathrm{Gy}_{\mathrm{RBE}}$ for chondrosarcoma patients at 1.8-2.0 $\mathrm{Gy}_{\mathrm{RBE}}$ per fraction. Relative biologic effectiveness (RBE) was defined as 1.1 [12]. GTV coverage was maximized with regard to OAR dose constraints. Patients were treated exclusively with single-field uniform dose (SFUD) until 2003 and afterwards with a combination of intensity modulated proton therapy (IMPT). The first treatment series was typically delivered with three- or four-field SFUD plans, including one or two opposed lateral fields with a small couch kick and two superior oblique fields. IMPT plans were optimized with four non-coplanar fields, two posterior oblique and two anterior oblique fields. Additional information regarding irradiation technique, planning objectives and OAR dose constraints, has been previously published [13].

\section{Follow-up evaluation}

Follow-up was performed in intervals of 3-6 months for the first 2-3 years and annually thereafter via clinical assessment and MRI, as well as CT imaging. Local control was defined as a reduction in tumor volume or stable disease comparing follow-up MRI and CT images with imaging prior proton therapy.

\section{Patterns of recurrence and DVH analysis}

An in-depth retrospective patterns of recurrence and dose volume histogram (DVH) analysis was performed. The initial target contour sets were exported from our in-house treatment planning system (PSIplan) into the treatment planning software Eclipse (Version 13.6, Varian Medical Systems, Palo Alto, USA) and used for both the patterns of recurrence and DVH analysis. The local recurrences were contoured on the respective follow-up MRI imaging studies, registered with the initial planning $\mathrm{CT}$ and MRI images and the newly generated structures (i.e. recurrences) were also exported into Eclipse to calculate the overlap of the local failures with the initial

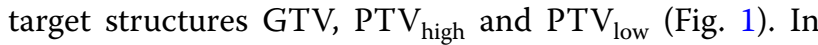
addition, individual DVH parameters of the initial planning structures were calculated for all 222 patients. The DVH parameters of patients with locally controlled tumors were statistically compared to the available DVH parameters of the patients who developed a local recurrence $(n=32$ patients).

\section{Statistical analysis}

Local control (LC) was assessed, comparing patients with and without recurrence, as well as with and without OAR involvement. Local control was defined as stable disease or tumor shrinkage, while radiologically 
Table 1 Patient characteristics of 222 patients treated with pencil-beam scanning proton therapy

\begin{tabular}{|c|c|c|c|c|}
\hline Parameter & Total $N=222$ & Chordoma $N=151$ & ChSa $N=71$ & $p$ value \\
\hline \multicolumn{5}{|l|}{ Age (years) } \\
\hline Mean (SD) & $40.8(18.4)$ & $43.3(18.1)$ & $35.6(18.3)$ & 0.004 \\
\hline \multicolumn{5}{|l|}{ Gender } \\
\hline Female (\%) & $105(47.3)$ & $65(43.0)$ & $40(56.3)$ & \multirow[t]{2}{*}{0.09} \\
\hline Male (\%) & $117(52.7)$ & $86(57.0)$ & $31(43.7)$ & \\
\hline \multicolumn{5}{|l|}{ Recurrent disease } \\
\hline No (\%) & $171(77)$ & $115(76.2)$ & $56(78.9)$ & \multirow[t]{2}{*}{0.76} \\
\hline Yes (\%) & $51(23)$ & $36(23.8)$ & $15(21.1)$ & \\
\hline \multicolumn{5}{|l|}{ GTV $(c c)$} \\
\hline Mean (SD) & $35.7(29.1)$ & $35.4(27.5)$ & $36.1(32.5)$ & 0.87 \\
\hline \multicolumn{5}{|l|}{ Brainstem compression } \\
\hline No (\%) & $151(68)$ & $100(66.2)$ & $51(71.8)$ & \multirow[t]{3}{*}{0.62} \\
\hline Abutment (\%) & $46(20.7)$ & $34(22.5)$ & $12(16.9)$ & \\
\hline Yes (\%) & $25(11.3)$ & $17(11.3)$ & $8(11.3)$ & \\
\hline \multicolumn{5}{|c|}{ Optic apparatus compression } \\
\hline No (\%) & $154(69.4)$ & $113(74.8)$ & $41(57.7)$ & \multirow[t]{3}{*}{0.03} \\
\hline Abutment (\%) & $44(19.8)$ & $26(17.2)$ & $18(25.4)$ & \\
\hline Yes (\%) & $24(10.8)$ & $12(7.9)$ & $12(16.9)$ & \\
\hline \multicolumn{5}{|l|}{ Any compression } \\
\hline No (\%) & $109(49.1)$ & $76(50.3)$ & $33(46.5)$ & \multirow[t]{2}{*}{0.7} \\
\hline Yes (\%) & $113(50.9)$ & 75 (49.7) & $38(53.5)$ & \\
\hline \multicolumn{5}{|l|}{ Surgery } \\
\hline Subtotal resection (\%) & $215(96.8)$ & 147 (97.3) & $68(95.8)$ & \multirow[t]{2}{*}{0.68} \\
\hline Complete resection (\%) & $7(3.2)$ & $4(2.7)$ & $3(4.2)$ & \\
\hline \multicolumn{5}{|l|}{ Number of surgeries } \\
\hline $1(\%)$ & $101(46.8)$ & $63(43.4)$ & $38(53.5)$ & \multirow[t]{6}{*}{0.013} \\
\hline $2(\%)$ & $78(36.1)$ & $59(40.7)$ & $19(26.8)$ & \\
\hline $3(\%)$ & $23(12.0)$ & $14(9.7)$ & $12(16.9)$ & \\
\hline $4(\%)$ & $6(2.8)$ & $6(4.1)$ & $0(0)$ & \\
\hline $5(\%)$ & $3(1.4)$ & $3(2.1)$ & $0(0)$ & \\
\hline $6(\%)$ & $2(0.9)$ & $0(0)$ & $2(2.8)$ & \\
\hline \multicolumn{5}{|c|}{ Postoperative complications } \\
\hline No (\%) & $154(69.4)$ & $106(70.2)$ & $48(67.6)$ & \multirow[t]{2}{*}{0.89} \\
\hline Yes (\%) & 68 (30.6) & 45 (29.8) & $23(32.4)$ & \\
\hline
\end{tabular}

Italics indicate statistically significant differences

confirmed tumor growth in subsequent images was considered a local failure/recurrence. In our previous study, we compared the prognostic potential of clinical (histology, patient's age, gender, compression of the brainstem or optic apparatus, tumor volume, recurrent status before PT) and technical (number of surgeries, weekly fractions) factors for both local control and overall survival (OS) [11]. In the present study, individual DVH parameters including $\mathrm{D}_{\min }, \mathrm{D}_{\max }, \mathrm{D} 98$, $\mathrm{D} 95, \mathrm{D}_{\text {mean }}, \mathrm{V} 70$, the volume receiving less than 66 $\mathrm{Gy}_{\mathrm{RBE}}\left(\mathrm{V}<66 \mathrm{~Gy} \mathrm{~V}_{\mathrm{RBE}}\right)$, and the volume receiving less than
$59 \operatorname{Gy}_{\mathrm{RBE}}\left(\mathrm{V}<59 \mathrm{~Gy}_{\mathrm{RBE}}\right)$ of initial planning structures and recurrences were calculated. These parameters were statistically compared between patients with and without locally controlled tumors to derive prognostic DVH parameters for LC via univariate and multivariate cox regression. To account for the outcome differences between skull base tumor histology, this was included as a categorial variable in the multivariate analysis. Concordance index (CI) was calculated for all Cox models. Statistical analysis was performed using R software. Tests were performed two-sided and differences 


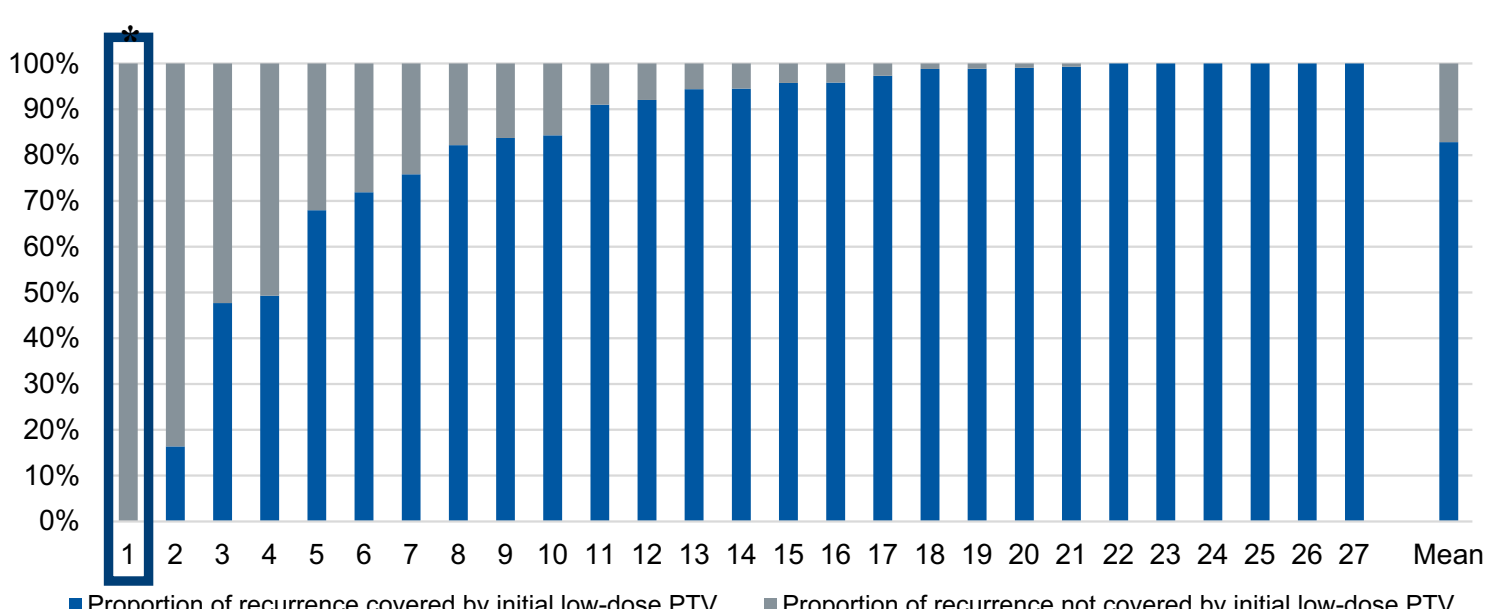

n Proportion of recurrence covered by initial low-dose PTV $\quad$ Proportion of recurrence not covered by initial low-dose PTV

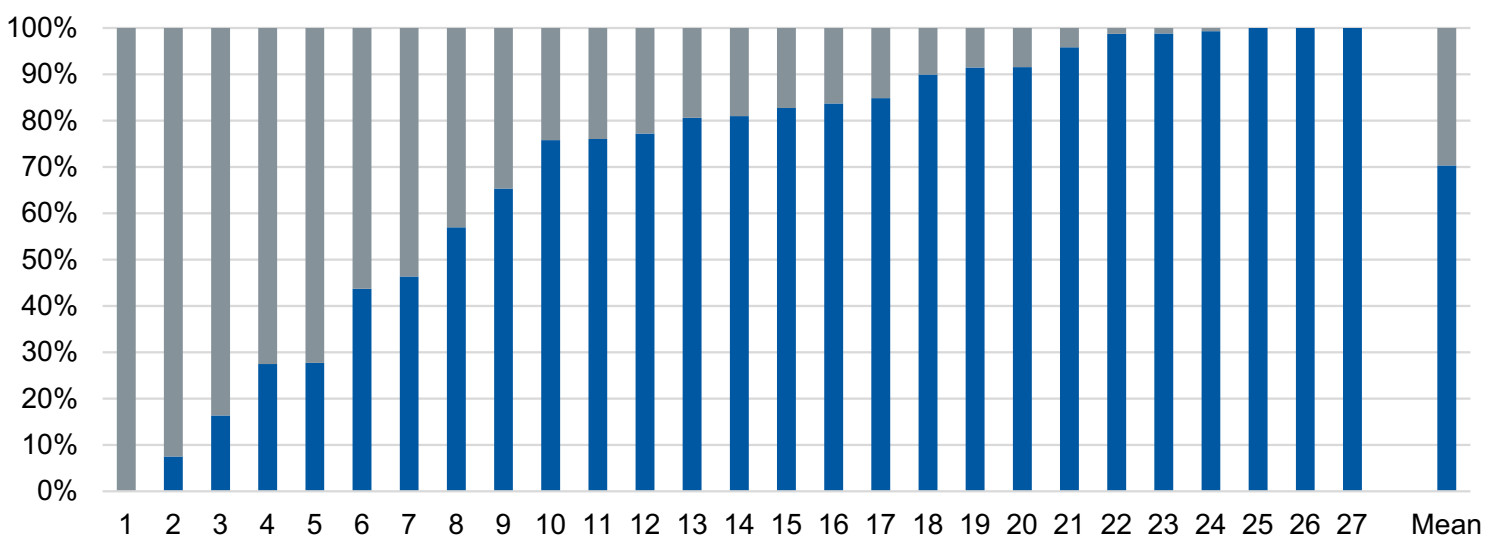

- Proportion of recurrence covered by initial high-dose PTV $\quad$ Proportion of recurrence not covered by initial high-dose PTV

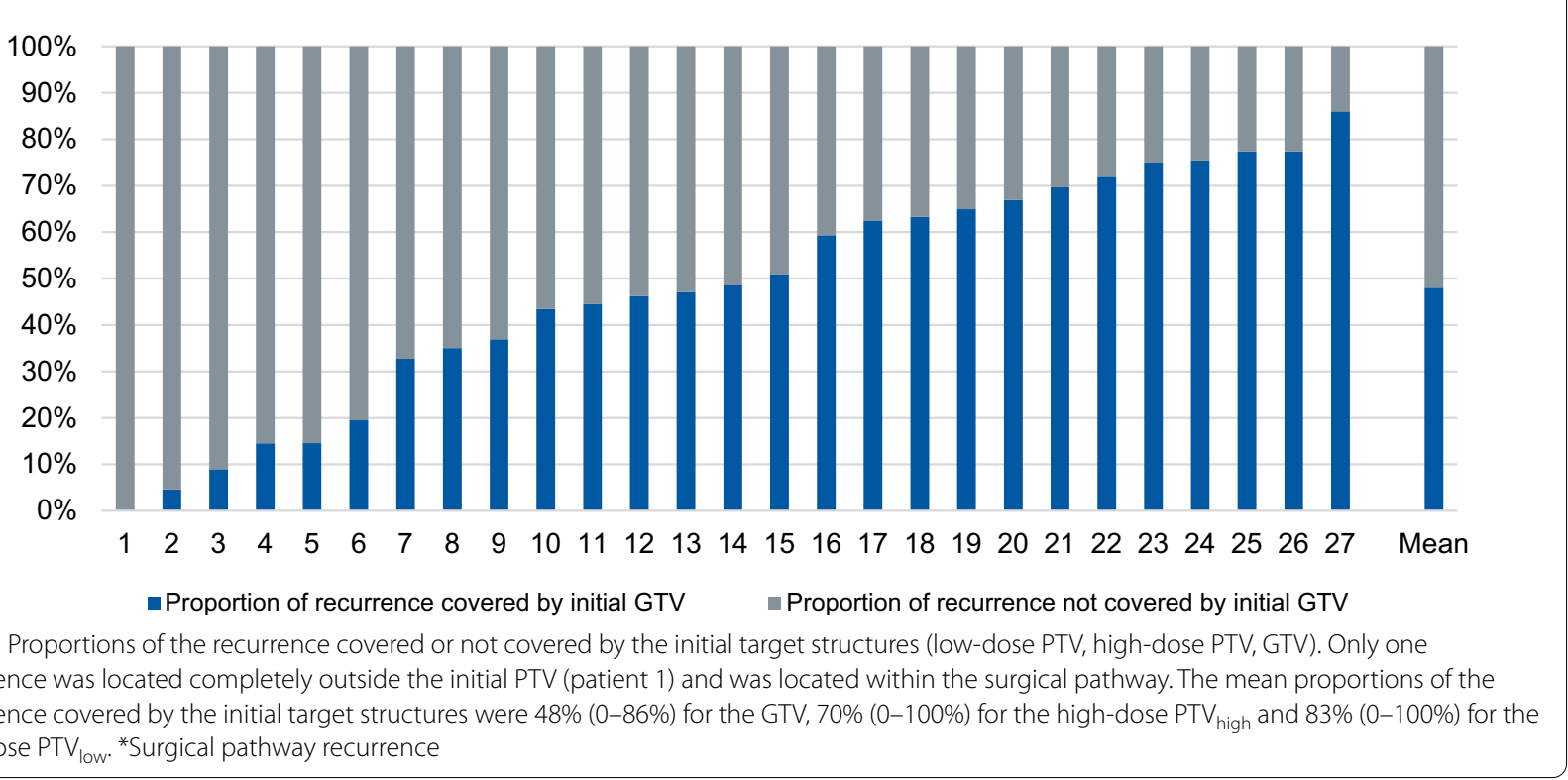


with a $p$ value below 0.05 were considered as statistically significant.

\section{Results}

After a median follow-up of 50 months (range 4-176), 35 (16\%) local failures were observed, $5(7 \%)$ in chondrosarcoma and $30(20 \%)$ in chordoma patients. As described in our previous analysis, the 5- and 7-year local control rates were $81 \%$ and $78 \%$ (all patients), $76 \%$ and $71 \%$ (chordoma) and 94\% (chondrosarcoma), respectively. Local control for chondrosarcomas was significantly better compared to chordomas $(p=0.04, \mathrm{CI}=0.59) .5$ - and 7 -year overall survival for the entire cohort were $86 \%$ and $80 \%$, respectively [11].

Follow-up MRI imaging, which was the basis for diagnosis of local recurrence, was available for 27 (77\%) of these 35 recurring patients. The initial PTV including DVH could be extracted for 213 (96\%) of the total studied cohort and for 32 (91\%) of the recurring patients. In some patients, only an initial CTV was available which led to a slight decrease in available GTV structures of 194 (87\%) for the total cohort. For the recurring patients, there was no difference and the initial GTV was available for 32 (91\%) patients. Thus, the dosimetric evaluation was based on the exported DVH data of 32 patients, while the patterns of recurrence analysis was performed on 27 patients where follow-up imaging was available. It is important to note that neither target delineation principles, nor treatment technique or planning objectives differed between recurring and non-recurring patients.

The overlap of the local failures with the initial target structures GTV, high-dose PTV $\mathrm{V}_{\text {high }}$ and low-dose PTV $\mathrm{V}_{\text {low }}$ was calculated. Only one recurrence was located completely outside the initial PTV (Fig. 1, patient 1) and was identified as a surgical pathway recurrence. The mean proportion of recurrence volumes covered by the initial target structures (overlap) were $48 \%$ for the initial GTV, ranging from $0 \%$ (surgical pathway recurrence) to $86 \%$ (local failure). The initial PTV $\mathrm{V}_{\text {high }}$ covered a mean of $70 \%$ of the recurrence volumes, ranging from 0 to $100 \%$. The larger $\mathrm{PTV}_{\text {low }}$ covered a mean of $83 \%$ of recurrence volumes, ranging from 0 to $100 \%$ (Fig. 1).

Three examples of in-field recurrences or marginal failures, together with the initial GTV (yellow) and PTV $_{\text {high }}$ (red) structures and dose distribution showing V59Gy $\mathrm{RBE}_{\mathrm{RE}}$ and $\mathrm{V} 66 \mathrm{~Gy} \mathrm{P}_{\mathrm{RBE}}$ (in color wash) are shown in Fig. 2. The dose of $66 \mathrm{~Gy}_{\mathrm{RBE}}$ corresponds to $95 \%$ of the prescription dose (D95) in most cases. The first example (A) shows a marginal failure in the ethmoid/frontal sinus, which may be due to lack of elective coverage in this area. In the second example (B), the initial PTV $\mathrm{V}_{\text {high }}$ (red) almost completely covers the recurrence (green) but because of the brainstem OAR constraint, the dose distribution is compromised in this area (right image). Example 3 (bottom) shows a marginal failure, likely because of chiasm OAR constraints.

The location of the recurrence was analyzed and categorized into three groups (brainstem, chiasm, other, Fig. 3). Recurrences that occurred in the area of the brainstem $(n=16,46 \%)$ had a tendency to compress or infiltrate the brainstem $(n=8,23 \%)$ or occurred in the cerebellopontine angle $(\mathrm{n}=4,11 \%)$ or the foramen magnum $(n=3,9 \%)$. Sphenoid sinus infiltration was rare $(n=1,3 \%)$. Recurrences occurring in the area of the chiasm $(n=13,37 \%)$ infiltrated the sphenoid sinus $(\mathrm{n}=8,23 \%)$ most frequently with only a small percentage of brainstem infiltration $(\mathrm{n}=2,6 \%)$ or progression to the frontotemporal brain tissue $(n=3,9 \%)$. Two of the recurred patients $(6 \%)$ had a recurrence in both the area of brainstem and chiasm. There were 6 recurrences $(17 \%)$ outside the brainstem or chiasm areas, $3(9 \%)$ in the frontotemporal brain, $2(6 \%)$ in the spinal area and one (3\%) surgical pathway recurrence in the skull.

In addition to the patterns of recurrence analysis, individual DVH parameters of initial planning structures and recurrences were calculated and correlated with local failure (Table 2). In the univariate analysis, we identified several conventional clinical DVH parameters, which were significantly associated with an increased risk of local recurrence. For the GTV the parameters were: GTV (D95, $p=0.05$ ), GTV volume receiving less than $66 \mathrm{~Gy}_{\mathrm{RBE}}\left(\mathrm{V}<66 \mathrm{~Gy}_{\mathrm{RBE}}, p=0.01\right)$, GTV volume $(p=0.02)$. For the $\mathrm{PTV}_{\text {high }}$ significant factors include: $\mathrm{PTV}_{\text {high }}\left(\mathrm{D}_{\max }, p=0.02\right), \mathrm{PTV}_{\text {high }}$ volume receiving less than $66 \mathrm{~Gy}_{\mathrm{RBE}}\left(\mathrm{V}<66 \mathrm{~Gy} \mathrm{RBE}_{\mathrm{RB}}\right.$, $p=0.03), \mathrm{PTV}_{\text {high }}$ volume receiving less than $59 \mathrm{~Gy}_{\mathrm{RBE}}$ $\left(\mathrm{V}<59 \mathrm{~Gy}_{\mathrm{RBE}}, p=0.02\right), \mathrm{PTV}_{\text {high }}$ volume $(p=0.01)$.

In the multivariate analysis, histology (chordoma vs chondosarcoma, $p=0.009)$, PTV volume $(p=0.045)$ and GTV $\left(\mathrm{V}<66 \mathrm{~Gy}_{\mathrm{RBE}}, p=0.022\right),(\mathrm{CI}=0.67)$ remained significant and were an independent prognostic factor for local tumor control. The GTV volume receiving less than $66 \mathrm{~Gy}_{\mathrm{RBE}}$ could differentiate between a 5-year local control rate of $65 \%\left(\mathrm{GTV}<66 \mathrm{~Gy}_{\mathrm{RBE}}>3 \mathrm{cc}\right)$ and $77 \%$ $\left(\mathrm{GTV}<66 \mathrm{~Gy}_{\mathrm{RBE}}<3 \mathrm{cc}\right)$ for chordoma and between $86 \%$ $\left(\mathrm{GTV}<66 \mathrm{~Gy}_{\mathrm{RBE}}>3 \mathrm{cc}\right)$ and $97 \%\left(\mathrm{GTV}<66 \mathrm{~Gy}_{\mathrm{RBE}}<3 \mathrm{cc}\right)$ for chondrosarcoma patients. The PTV volume could differentiate between a 5-year local control rate of $57 \%(\mathrm{PTV}>120 \mathrm{cc})$ and $78 \%(\mathrm{PTV}<120 \mathrm{cc})$ for chordoma and between 73\% (PTV >120 cc) and 97\% $(\mathrm{PTV}<120 \mathrm{cc})$ for chondrosarcoma patients. Figure 4 details the Kaplan Meier curves of local control in dependence of $\mathrm{PTV}_{\text {high }}$ volume and GTV volume receiving less than $66 \mathrm{~Gy}_{\mathrm{RBE}}$ separately for both chordoma and chondrosarcoma patients. 


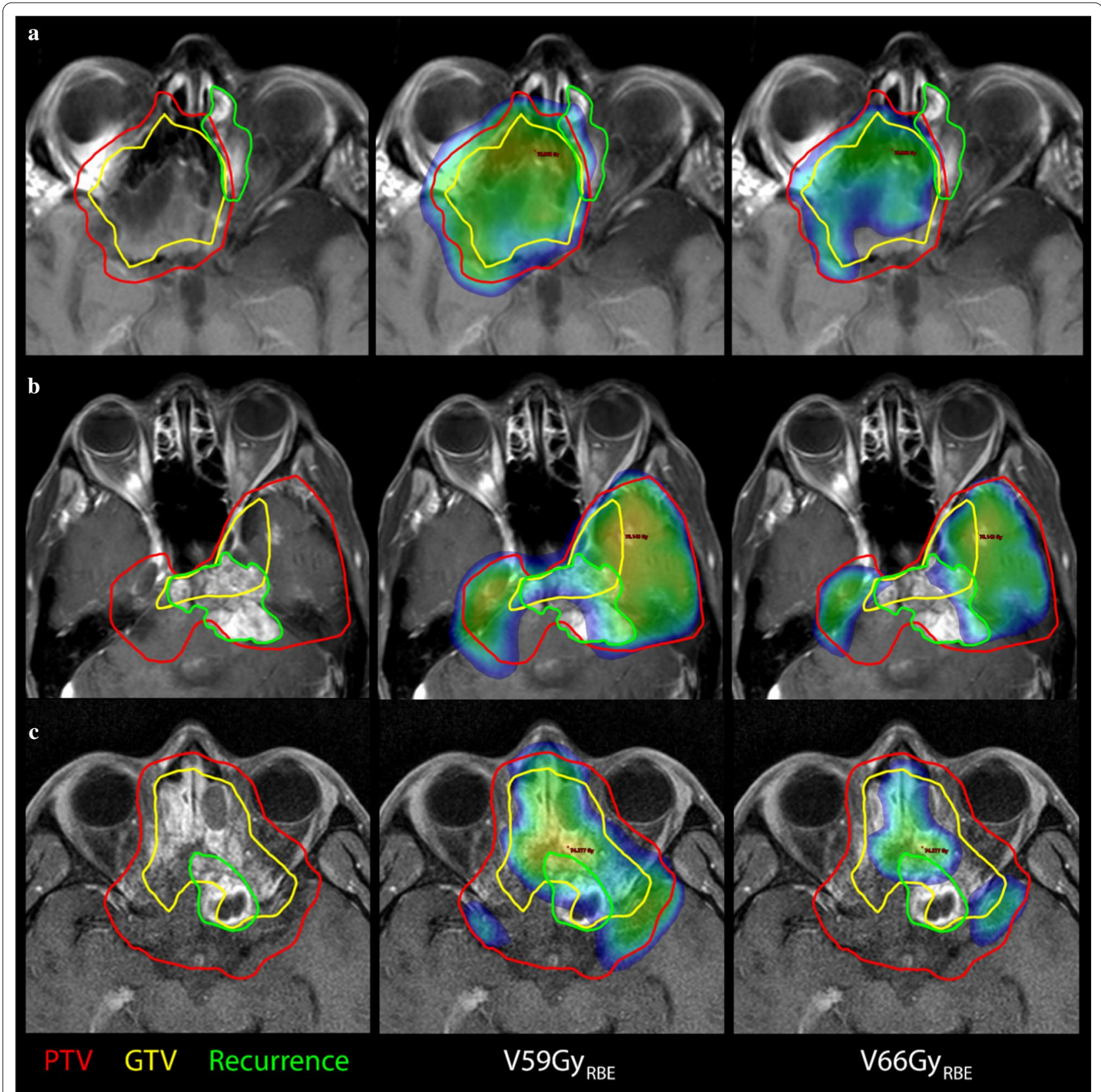

Fig. 2 Three examples of in-field recurrences (green) or marginal failures, together with the initial GTV (yellow) and PTV high (red) structures and dose distribution showing V59Gy $\mathrm{RBE}_{\text {and }}$ V66GY $\mathrm{RBE}_{\mathrm{RE}}$ (in color wash). The dose of $66 \mathrm{~Gy}_{\mathrm{RBE}}$ corresponds to the 95\% covering isodose (D95) in most cases. The first example (a) shows a marginal failure in the ethmoid/frontal sinus due to lack of elective coverage in this area. In the second example (b), the initial PTV high (red) nearly completely covers the recurrence (green) but because of the brainstem OAR constraint, the dose distribution is compromised in this area (right image). Example 3 (c) shows a marginal failure because of chiasm OAR constraints

\section{Discussion}

Despite combined modality treatment involving surgery and adjuvant radiotherapy, a relevant percentage of chordoma and chondrosarcoma patients develop a local recurrence [8-10]. A reason might be the close proximity or involvement/compression of critical OARs, including but not limited to the brainstem, optic chiasm and optic nerves, making complete surgical resection and the safe delivery of radiation of these tumors challenging. Unfortunately, in most cases, we currently lack prognostic parameters to assess the risk of local failure for an individual patient. 


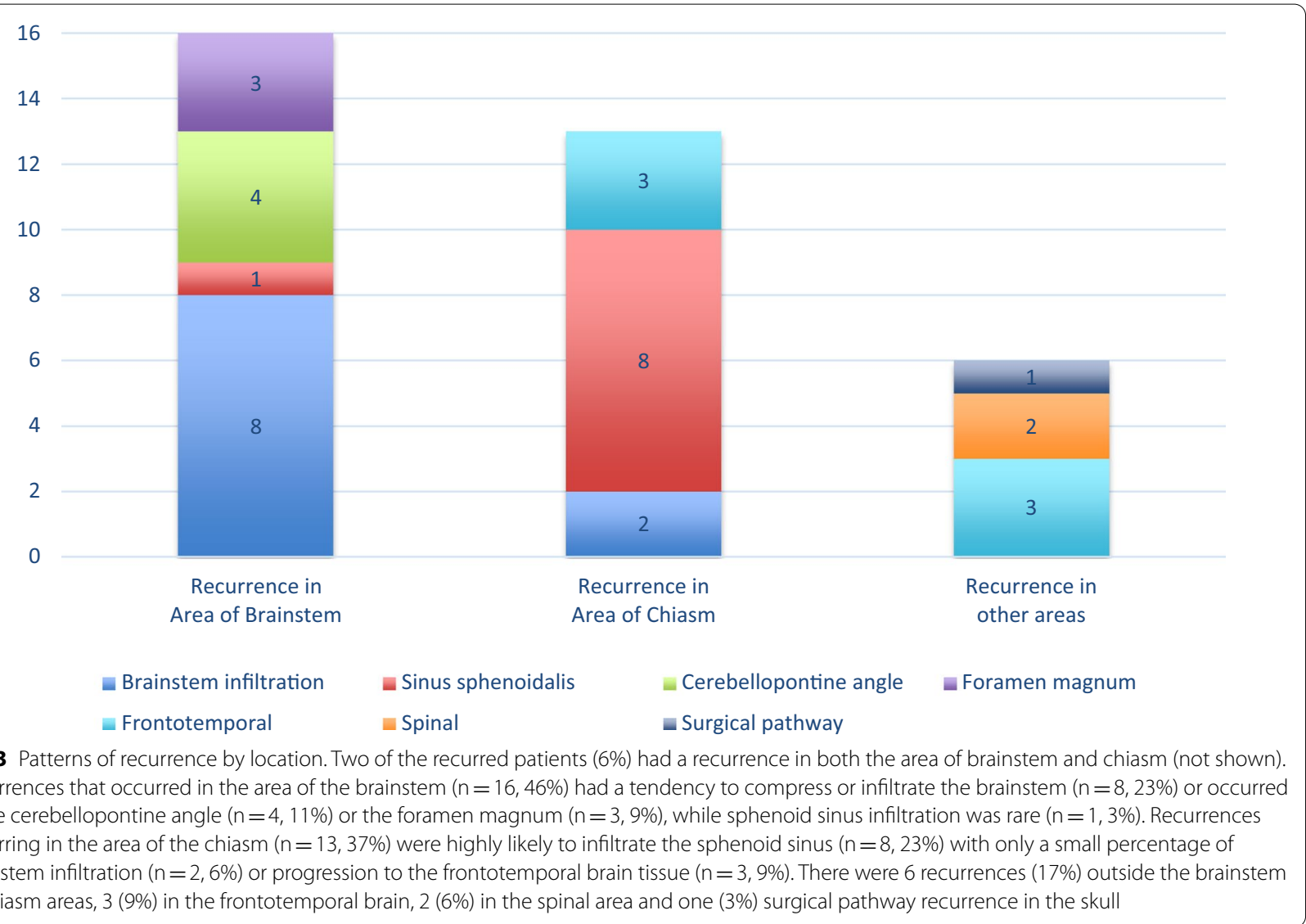

Table 2 Prognostic DVH parameters

\begin{tabular}{|c|c|c|c|c|c|}
\hline \multicolumn{2}{|c|}{ DVH parameters and histology } & \multicolumn{2}{|c|}{$\begin{array}{l}\text { Univariate } \\
\text { analysis }\end{array}$} & \multicolumn{2}{|c|}{$\begin{array}{l}\text { Multivariate } \\
\text { analysis }\end{array}$} \\
\hline & & $p$ value & $\mathrm{Cl}$ & $p$ value & $\mathrm{Cl}$ \\
\hline GTV & D95 (\%) & 0.05 & 0.59 & ns & ns \\
\hline GTV & $V<66 G y_{R B E}$ & 0.01 & 0.62 & 0.022 & 0.67 \\
\hline GTV & Volume & 0.02 & 0.64 & ns & ns \\
\hline PTV $V_{\text {high }}$ & Max dose $G y_{\text {RBE }}$ & 0.02 & 0.61 & ns & ns \\
\hline PTV high $_{\text {n }}$ & $V<66 \mathrm{~Gy} \mathrm{RBE}_{\mathrm{RBE}}$ & 0.03 & 0.63 & ns & ns \\
\hline PTV $V_{\text {high }}$ & $V<59 G y_{R B E}$ & 0.02 & 0.62 & ns & ns \\
\hline PTV $V_{\text {high }}$ & Volume & 0.01 & 0.63 & 0.045 & 0.67 \\
\hline Histology & $\begin{array}{l}\text { Chordoma versus } \\
\text { chondrosarcoma }\end{array}$ & - & - & 0.009 & 0.67 \\
\hline
\end{tabular}

Italics indicate statistically significant differences

In the univariate analysis, the following DVH parameters were significantly associated with an increased risk of local recurrence: GTV D95 $(p=0.05)$, GTV volume receiving less than $66 \mathrm{~Gy}_{\mathrm{RBE}}\left(\mathrm{V}<66 \mathrm{~Gy}_{\mathrm{RBE}} p=0.01\right)$, $\mathrm{GTV}$ volume $(p=0.02)$, PTV maximum dose $(p=0.02)$, PTV volume receiving less than $66 \mathrm{~Gy}_{\mathrm{RBE}}\left(\mathrm{V}<66 \mathrm{~Gy}_{\mathrm{RBE}}, p=0.03\right)$, $\mathrm{PTV}$ volume receiving less than $59 \mathrm{~Gy}_{\mathrm{RBE}}$ $\left(\mathrm{V}<59 \mathrm{~Gy}_{\mathrm{RBE}}, p=0.02\right)$, PTV volume $(p=0.01)$. In the multivariate analysis, histology (chordoma vs chondosarcoma, $p=0.009)$, PTV volume $(p=0.045)$ and GTV $(\mathrm{V}<66 \mathrm{GyRBE}, p=0.022),(\mathrm{Cl}=0.67)$ presented as independent prognostic factors of local tumor control
In our previous analysis, we could show that skullbase tumor patients treated with pencil-beam scanning proton therapy have a favorable outcome with a 7 -year OS and LC of $80 \%$ and $78 \%$, respectively [11]. These results compare favorably with a recently published meta-analysis about intracranial chordoma [14]. In addition, we identified optic apparatus and/or brainstem compression and histology as prognostic factors for the risk of local failure.

Another important finding was that GTV volume could be identified as an independent prognostic factor of local control, which could be confirmed in the current analysis in addition to PTV volume (Table 2). This provides a strong basis for the evaluation of a potential re-resection before PT, whenever possible, to reduce the risk of local recurrence. In a recently published meta-analysis the extent of surgical resection of 670 chordoma patients from 15 studies was analyzed [14]. The weighted mean percentage of patients receiving gross total resection was $29 \%$, while subtotal resection was achieved in $61 \%$ and partial resection in $20 \%$ of cases. This suggests that complete resection or re-resection is not always feasible and that we might need to include additional parameters with prognostic potential to assess the risk of local recurrence 
(See figure on next page.)

Fig. 4 Local control in dependence of PTV high volume and GTV volume receiving less than 66G $\mathrm{V}_{\text {RBE }}$ separately for both chordoma and chondrosarcoma patients. Apart from tumor histology (chordoma vs chondosarcoma, $p=0.009$ ), both PTV high volume $(p=0.045)$ and GTV $\left(\mathrm{V}<66 \mathrm{GY}_{\mathrm{RBE}}, p=0.022\right)$ were significant independent prognostic factors of local failure in the multivariate analysis. The PTV volume could differentiate between a 5-year local control rate of 57\% (PTV> $120 \mathrm{cc}$ ) and 78\% (PTV < $120 \mathrm{cc}$ ) for chordoma (a) and between 73\% (PTV>120 cc) and $97 \%\left(P T V<120 \mathrm{cc}\right.$ ) for chondrosarcoma patients (c). The GTV volume receiving less than 66Gy ${ }_{\text {RBE }}$ could differentiate between a 5-year local

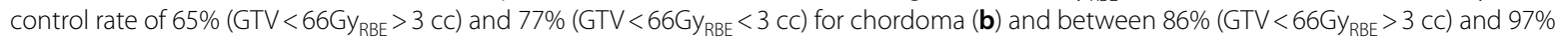
$\left(\mathrm{GTV}<66 \mathrm{~Gy} \mathrm{RBE}_{\mathrm{RB}}<3 \mathrm{cc}\right)$ for chondrosarcoma patients $(\mathbf{d})$

and differentiate between patients with better or worse outcomes.

In this study, we could for the first time, identify prognostic DVH parameters for proton therapy delivered to chordomas and chondrosarcomas, which are associated with an increased risk of local recurrence in these patients. In our analysis, local control for chondrosarcomas was significantly better compared to chordomas, which is in line with other studies [15]. To account for the differences in radiation sensitivity of chordoma and chondrosarcoma patients, tumor histology was included as a categorial variable in the multivariate analysis and could be confirmed as an independent prognostic factor for local control. In addition, PTV volume and the GTV volume receiving less than $66 \mathrm{~Gy}_{\mathrm{RBE}}$ were independent prognostic factors. It should be mentioned that many of the analyzed parameters are conventional DVH parameters, and although they were not independent predictors of local failure, multiple GTV and PTV parameters were prognostic in the univariate analysis. This suggests that it might be feasible to assess the risk of local recurrence from these conventional DVH parameters, used in daily clinical routine.

Our patterns of recurrence analysis, based on 27 follow-up MRI studies of 35 patients with local recurrence, indicates that our delineation paradigm was clinically appropriate, with only one case of a surgical pathway recurrence ( $0.5 \%$ of total patients), which was not covered by the initial PTV. This point is highly relevant due to the absence of published guidelines for these challenging tumors. All other recurrences were either completely or at least partially covered by the initial target volumes $\left(G T V, \mathrm{PTV}_{\text {high }}, \mathrm{PTV}_{\text {low }}\right)$. This suggests that the recurrences have developed from the initial tumor, growing into and/or infiltrating adjacent organs subsequently. The applied dose to the tumor might have been insufficient in these cases due to OAR constraints and/or the tumor cells might have been particularly radioresistant, which is however difficult to assess retrospectively (e.g. biological/ molecular analysis).
In addition, the differing time intervals between the proton treatment and available follow-up imaging of the recurrences makes it difficult to compare the coverage of the recurrences by the initial target volumes. In some cases, a longer time interval might have led to an increased tumor growth outside the initial PTV or GTV.

So far, no contouring guidelines about chordomas and chondrosarcomas of the skull-base have been published, thus our analysis might provide a basis for clinical decision making and risk assessment of an individual skullbase tumor patient. Regarding target volume delineation, it should be noted that the sphenoid sinus should be covered in case of chiasm involvement, as patients with tumors in this location had a high risk of local recurrence in the sphenoid sinus in our analysis.

There are several limitations of this study, including the long time interval between the first treated patient in 1998 and the last patient of this analysis in 2012. The available imaging, imaging quality and to some extent treatment planning changed slightly over time and image registration of the recurrences can be a challenging process. Some patients were treated with single-field uniform dose (SFUD) and others with intensity modulated proton therapy (IMPT). It also needs to be mentioned that local tumor control could also be achieved in a proportion of patients, whose DVH characteristics did not fully meet the planning objectives, suggesting that individual radiation resistance may be an additional important factor. In addition, the retrospective character of our analysis is prone to bias. Strengths of our analysis include the large patient cohort, inclusion of modern IMPT techniques, as well as the high percentage of available followup imaging for the recurred patients.

In summary, we were able to identify prognostic DVH parameters, associated with the risk of local recurrence in chordoma and chondrosarcoma patients treated with proton therapy. We have shown that the residual tumor volume and the coverage of the PTV was of paramount importance. These metrics may be used for clinical decision making when treating these challenging patients, although confirmatory results are required. 


\section{Chordoma}
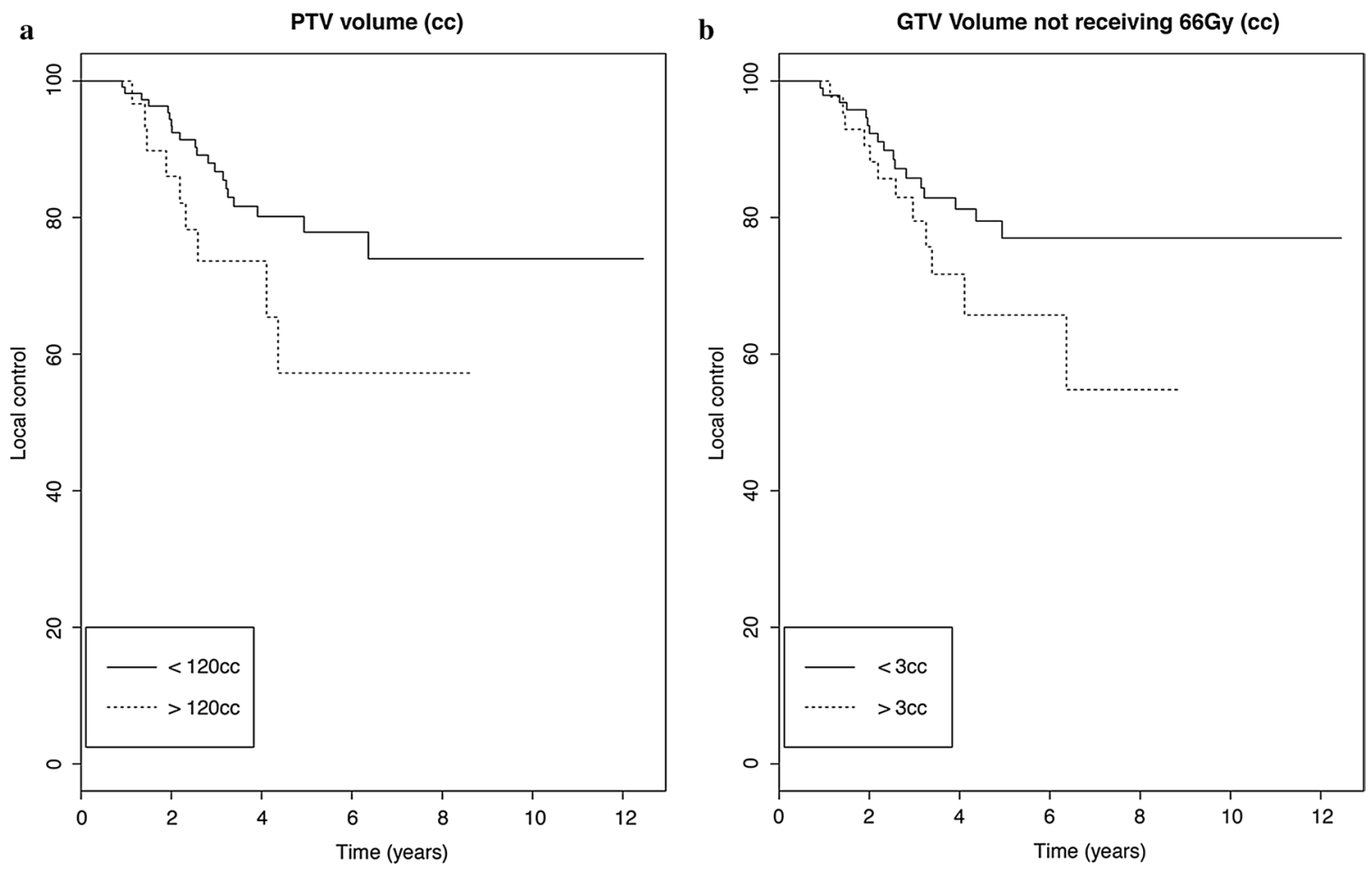

\section{Chondrosarcoma}

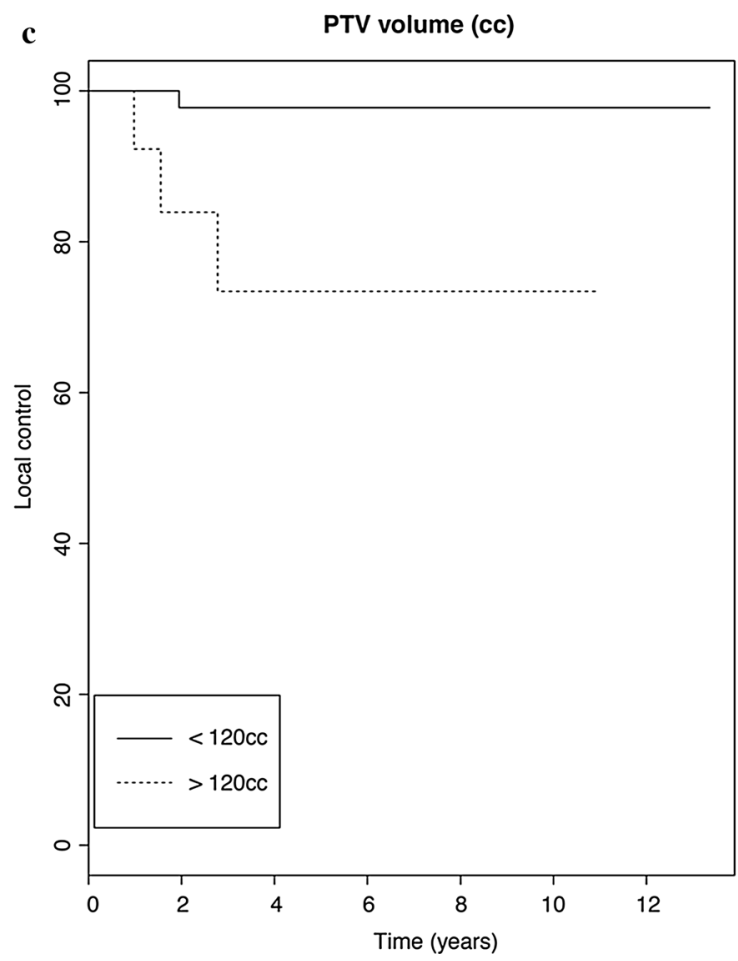

d

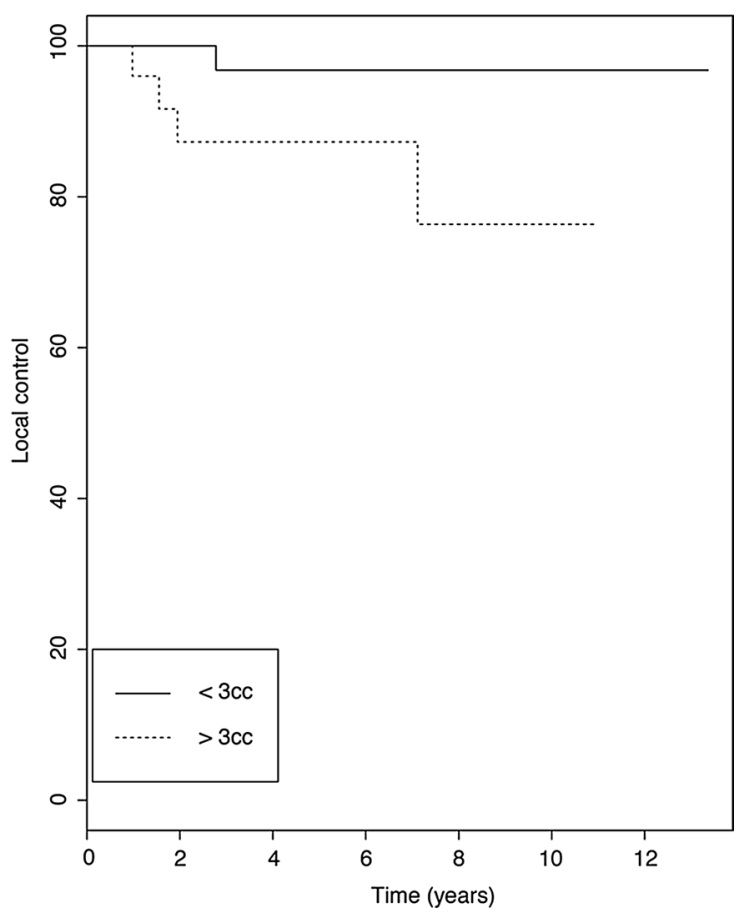




\section{Abbreviations}

Cl: Concordance index; CTV: Clinical target volume; DVH: Dose volume histogram; GTV: Gross tumor volume; IMPT: Intensity modulated proton therapy; LC: Local control; LR: Local recurrence; OAR: Organs of risk; OS: Overall survival; PBS: Pencil-beam scanning; PSI: Paul Scherrer Institute; PTV: Planning target volume; RBE: Relative biologic effectiveness; SFUD: Single-field uniform dose.

\section{Acknowledgements}

Not applicable.

\section{Authors' contributions}

LB contoured the recurrences, analyzed the patterns of recurrence by location and created the manuscript figures. LB and RP exported, analyzed and interpreted the dosimetric data regarding the skullbase recurrences. STL performed the univariate and multivariate statistical analysis. All authors read and approved the final manuscript.

\section{Funding}

None.

\section{Availability of data and materials}

The datasets used and/or analysed during the current study are available from the corresponding author on reasonable request.

\section{Ethics approval and consent to participate}

Written informed consent was obtained from all patients and the study was approved by the local ethics committee (Kantonale Ethikkommission Nordwest- und Zentralschweiz (EKNZ, approval number 2020-01071) in accordance with 'good clinical practice' (GCP) guidelines and the Declaration of Helsinki.

\section{Consent for publication}

Not applicable.

\section{Competing interests}

The authors declare that they have no competing interests.

\section{Author details}

${ }^{1}$ Center for Proton Therapy, Paul Scherrer Institute, ETH Domain, Forschungsstrasse 111, 5232 Villigen, Switzerland. ${ }^{2}$ Department of Radiation Oncology, University Hospital Zürich, University of Zurich, Zurich, Switzerland. ${ }^{3}$ Department of Radiation Oncology, University Hospital Bern, University of Bern, Bern, Switzerland.

Received: 17 July 2020 Accepted: 6 November 2020

Published online: 16 November 2020

\section{References}

1. Smoll NR, Gautschi OP, Radovanovic I, Schaller K, Weber DC. Incidence and relative survival of chordomas: the standardized mortality ratio and the impact of chordomas on a population. Cancer. 2013;119:2029-37.

2. Healey JH, Lane JM. Chordoma: a critical review of diagnosis and treatment. Orthop Clin North Am. 1989;20:417-26.
3. Bloch O, Parsa AT. Skull base chondrosarcoma: evidence-based treatment paradigms. Neurosurg Clin N Am. 2013;24:89-96.

4. Oghalai JS, Buxbaum JL, Jackler RK, McDermott MW. Skull base chondrosarcoma originating from the petroclival junction. Otol Neurotol. 2005:26:1052-60

5. Weber DC, Badiyan S, Malyapa R, Albertini F, Bolsi A, Lomax AJ, et al. Long term outcomes and prognostic factors of skull-base chondrosarcoma patients treated with pencil-beam scanning proton therapy at the Paul Scherrer Institute. Neuro Oncol. 2016:18:236-43.

6. MacDonald SM, Trofimov A, Safai S, Adams J, Fullerton B, Ebb D, et al. Proton radiotherapy for pediatric central nervous system germ cell tumors: early clinical outcomes. Int J Radiat Oncol Biol Phys. 2011;79:121-9.

7. Blattmann H, Coray A, Pedroni E, Greiner R. Spot scanning for $250 \mathrm{MeV}$ protons. Strahlenther Onkol. 1990;166:45-8.

8. Uhl M, Mattke M, Welzel T, Oelmann J, Habl G, Jensen AD, et al. High control rate in patients with chondrosarcoma of the skull base after carbon ion therapy: first report of long-term results. Cancer. 2014;120:1579-85.

9. Uhl M, Mattke M, Welzel T, Roeder F, Oelmann J, Habl G, et al. Highly effective treatment of skull base chordoma with carbon ion irradiation using a raster scan technique in 155 patients: first long-term results. Cancer. 2014;120:3410-7.

10. Feuvret L, Bracci S, Calugaru V, Bolle S, Mammar H, De Marzi L, et al. Efficacy and safety of adjuvant proton therapy combined with surgery for chondrosarcoma of the skull base: a retrospective, population-based study. Int J Radiat Oncol Biol Phys. 2016;95:312-21.

11. Weber DC, Malyapa R, Albertini F, Bolsi A, Kliebsch U, Walser M, et al. Long term outcomes of patients with skull-base low-grade chondrosarcoma and chordoma patients treated with pencil beam scanning proton therapy. Radiother Oncol. 2016;120:169-74.

12. Paganetti $H$. Relative biological effectiveness (RBE) values for proton beam therapy. Variations as a function of biological endpoint, dose, and linear energy transfer. Phys Med Biol. 2014;59:R419-72.

13. Ares C, Hug EB, Lomax AJ, Bolsi A, Timmermann B, Rutz HP, et al. Effectiveness and safety of spot scanning proton radiation therapy for chordomas and chondrosarcomas of the skull base: first long-term report. Int J Radiat Oncol Biol Phys. 2009;75:1111-8.

14. Leah P, Dower A, Vescovi C, Mulcahy M, Al KD. Clinical experience of intracranial chordoma - a systematic review and meta-analysis of the literature. J Clin Neurosci. 2018;53:6-12.

15. Hug EB, Loredo LN, Slater JD, DeVries A, Grove RI, Schaefer RA, et al. Proton radiation therapy for chordomas and chondrosarcomas of the skull base. J Neurosurg. 1999;91:432-9.

\section{Publisher's Note}

Springer Nature remains neutral with regard to jurisdictional claims in published maps and institutional affiliations.
Ready to submit your research? Choose BMC and benefit from:

- fast, convenient online submission

- thorough peer review by experienced researchers in your field

- rapid publication on acceptance

- support for research data, including large and complex data types

- gold Open Access which fosters wider collaboration and increased citations

- maximum visibility for your research: over $100 \mathrm{M}$ website views per year

At $\mathrm{BMC}$, research is always in progress.

Learn more biomedcentral.com/submissions 